\title{
Psicanálise e Direito: escutar o sujeito no âmbito das medidas socioeducativas
}

\section{Psychoanalysis and Law: listening to the subject in the context of socio-educational measures}

\section{Juliana Marcondes Pedrosa de Souza*}

Pontifícia Universidade Católica de Minas Gerais - PUC-MG, Belo Horizonte, Minas Gerais, Brasil

\section{J acqueline de Oliveira Moreira**}

Pontifícia Universidade Católica de Minas Gerais - PUC-MG, Belo Horizonte, Minas Gerais, Brasil

\begin{abstract}
RESUMO
Neste artigo pretendemos refletir sobre as inovações do Estatuto da Criança e do Adolescente (ECA) a respeito da intervenção junto a crianças e adolescentes autores de ato infracional, e apresentar as contribuições da psicanálise por meio da escuta singularizada. Pensaremos as possibilidades e limites das medidas socioeducativas como uma ação que convoca à produção de sujeitos. Considerando que o sujeito para o discurso psicanalítico é atravessado por um desamparo estrutural que anuncia a importância fundamental da sua inscrição na relação com o outro, faz-se necessária uma apresentação das diferenças entre os conceitos de sujeito subjacentes aos discursos jurídico e psicanalítico. É preciso, ainda, fazer um breve histórico das posições jurídicas adotadas a respeito da criança e do adolescente. Encerramos com a apresentação de um caso ilustrativo. Concluímos que as medidas socioeducativas propõem a reinserção social, a readaptação, o ajustamento social, a integração à família e à sociedade. A psicanálise sustenta que a construção de um novo projeto de vida só é possível no trabalho com o sujeito enquanto aquele que, por meio da palavra, poderá, de modo singular, responsabilizar-se por seus atos.
\end{abstract}

Palavras-chave: medidas socioeducativas, psicanálise, subjetividade, desamparo.

\begin{abstract}
In this article we intend to reflect upon innovations on the Statute of Children and Adolescents regarding intervention with children and adolescents who have perpetrated misdemeanors, and to present the contributions offered by Psychoanalysis through singularized listening. We will think of the possibilities and limitations of socio-educational measures as an action which calls for the production of subjects. Whereas the subject for psychoanalytic discourse is crossed by a structural abandonment announcing the fundamental importance of their position in relation to the other, it is necessary to present the differences between the juridical and the psychoanalytic concepts of subject. It is also necessary to examine the
\end{abstract}


attitude of the Law towards children and adolescents throughout history. We finish with an illustrative case. We conclude that socio-educational measures intend to promote reinsertion in society, readaptation, social adjustment, integration to family and society. Psychoanalysis advocates that the construction of new project is only possible when the subject, by means of words, can be responsible for his or her actions, singularly.

Keywords: socio-educational measures, psychoanalysis, subjectivity, abandonment.

\section{Vicissitudes do sujeito moderno: da razão à lógica do inconsciente}

A categoria de sujeito surge na modernidade de tal modo que as posições filosóficas, políticas, sociais e culturais propiciam a valorização de uma concepção de subjetividade racional, na medida em que o sujeito passa ocupar o lugar de fundamento do conhecimento. Entretanto, apesar das várias explicações científicas dadas às expressões de sentidos presentes no pensamento moderno, não foi possível garantir pleno uso da razão. Neste cenário, de um sujeito determinado pela supremacia da razão, surgem a proposta da divisão da mente e a defesa do sistema inconsciente. Assim, é importante entender que a criação do sujeito moderno responde uma exigência histórica.

A revolução científica que propõe uma nova concepção de universo, o universo infinito, coloca questões cruciais para o sujeito moderno. $O$ universo não é mais o cosmos organizado dos gregos. É, agora, um espaço infinito, e não faz mais sentido a discussão sobre o seu centro. O homem se vê perdido neste universo sem fim, e tenta pensar sobre sua própria vida, seu significado e finalidade. $\mathrm{Na}$ verdade, o homem é um ser à deriva no universo infinito.

O novo, o estranho deve ser controlado, mas para controlar o mundo, o sujeito deve controlar a si mesmo, fazer da sua subjetividade, através da autodisciplina, uma plataforma firme, uma garantia de certeza.

Assim, a subjetividade emerge e se transforma no referencial central para o conhecimento. Cabe-nos, no entanto, salientar que essa subjetividade emergente se difere da noção contemporânea de sujeito. Descartes $(1641 / 1983)$ preocupa-se em criar um critério de verdade e certeza e, assim, deve-se realizar uma cisão metódica no sujeito e excluir tudo o que possa conduzir ao erro. Dessa forma, o sujeito de afeto, paixões, sentimento e "devires" deve ser excluído, expurgado. Devemos trabalhar com o sujeito da consciência e da racionalidade. Comentando essa questão, Bezerra (1989) revela:

(...) a emergência da questão da subjetividade nos primórdios do pensamento moderno não implica o aparecimento da 
questão do sujeito tal como hoje é pensada. A reflexão cartesiana em torno do "penso, logo sou" acentua a importância do verbo, e não do pronome. A singularidade do eu não está em pauta... (p. 228)

O cogito cartesiano alicerçou o projeto da modernidade que propõe a independência do sujeito pela via da razão, ou seja, o projeto de um sujeito racional, emancipado e livre. Vários são os desdobramentos do cogito cartesiano na modernidade. A ciência fomentou a articulação de uma gama de elaborações conceituais que se constituíram como elementos fundamentais para a construção do conhecimento científico e racional, a exemplo da questão da verdade universal, da objetividade absoluta e da neutralidade do sujeito pesquisador.

Assim, a categoria do sujeito entra em cena no mundo filosófico marcando a presença da metafísica da consciência. O sujeito filosófico representa o substrato último de garantia do conhecimento. E é justamente contra essa tradição metafísica da presença do sujeito pleno que Freud, com o conceito de Inconsciente, irá criticar a filosofia.

Com as descobertas de Freud, em 1900, a teoria psicanalítica sustenta que existe na vida do sujeito um determinismo que advém do inconsciente. Quando Freud lança a célebre frase: "fale tudo o que Ihe vier à cabeça" e convoca o sujeito a dizer livremente, rompendo com as influências da consciência, ele demonstra como o discurso se organiza pelas leis do inconsciente. As associações, as palavras e as expressões apresentam uma lógica não racional, sem sentido para a ciência positivista. Dessa forma, a psicanálise demonstra que a verdade do sujeito é singular, que está presente em seu discurso, e não na objetividade discursiva. A verdade do sujeito refere-se ao sujeito do inconsciente, e se apresenta por um enigma.

(...) a noção central de inconsciente implica: o sujeito é movido por forças que desconhece, o verdadeiro sentido de suas experiências está onde sua consciência não pode chegar, ele é um trágico personagem sempre tentando compreender e interpretar as motivações desconhecidas que o governam. (Bezerra, 1989, p. 232)

Considerando o conceito de sujeito do inconsciente proposto pela psicanálise, é possível afirmar, segundo Moreira (2003), que a teoria psicanalítica desloca a concepção de sujeito enlaçada com a consciência e dominada pela razão para o sujeito do inconsciente, determinado por leis próprias que extrapolam as possibilidades do sujeito racional. A proposta freudiana opera um descentramento na noção de sujeito moderno. A psicanálise associa a subjetividade aos 
temas do inconsciente, do desamparo, da pulsão, da alteridade, da responsabilidade. Há nos textos freudianos uma progressiva percepção da absoluta presença e necessidade do outro na relação com o eu. Essa progressão acompanha a percepção do desamparo como uma marca, uma ferida incurável tematizada sob o signo da pulsão de morte e do conceito de angústia e sob a consciência crescente do sentido trágico da problemática edípica. O Outro se faz presente na constituição do sujeito desde o primeiro momento, mas, o desamparo humano anuncia a necessidade da presença do outro como estrutura estruturante. Assim, a categoria de desamparo convoca o tema da alteridade e, por sua vez, se abre para a discussão ética em que o problema do reconhecimento e da responsabilidade são centrais.

Ademais, as inovações lacanianas apresentam o sujeito como um efeito de linguagem e acentuam a importância da dialética do reconhecimento na constituição subjetiva. Todas essas categorias são fundamentais para pensar o tema do sujeito na psicanálise, mas nesta reflexão sobre a escuta do sujeito no âmbito das medidas socioeducativas, gostaríamos de privilegiar o tema do desamparo, do reconhecimento e da responsabilidade. Ao apostarmos na psicanálise como um saber que orienta os profissionais que trabalham no acompanhamento desses adolescentes, sustentamos uma intervenção que vai além do acesso às políticas públicas de garantia de direitos pautadas em uma responsabilização de viés jurídico. Para tanto o reconhecimento dos aspectos subjetivos no campo do direito são fundamentais.

Assim, iniciaremos pelo tema do desamparo porque é nossa condição primordial. Podemos pensar que "a vida, em seu estado puro e bruto, não é necessariamente humana; é preciso a acolhida do outro para circunscrever essa vida no campo humano" (Moreira, 2010, p. 54). O outro contém e coloca os limites para o excesso que é a vida em seu estado bruto através da simbolização, sendo que essa ação porta em si uma ambiguidade: se de um lado oferece um certo amparo, de outro apresenta a face nua da "inssocorribilidade humana". A experiência do nascimento pode ser pensada como um lançamento na vida caótica, no excesso de energia sem tratamento, sem contenção. O outro filtra a realidade, permitindo que a criança receba pequenas doses do mundo real. Essa intromissão originária do outro é violenta e traumática, mas também é constitutiva da vida humana. A mãe não deve deixar o bebê à mercê de seu próprio excesso pulsional. Segundo Marin (1996) "negar" a violência primordial da presença constitutiva e traumática do outro pode deixar o sujeito à mercê de suas forças pulsionais, o que pode gerar uma ilusão de onipotência duplamente mortífera: morte do outro e do eu.

Desta forma, a questão do desamparo coloca, necessariamente, o tema da alteridade e do reconhecimento. O sujeito se constitui na 
relação com o outro e, sobretudo, na relação de reconhecimento. Não se pode prescindir do Outro no processo de constituição subjetiva, e desde então está colocada para o sujeito, segundo Lacan (1998), na sua proposta do estágio do espelho, a questão do reconhecimento como decisivo nesse processo de constituição. O sujeito precisa de se ver no olho do Outro, mas ainda é preciso um passo além, que é o reconhecimento do limite, da castração, e assim assentir em uma posição de sujeito barrado.

O sujeito não pode ser compreendido, segundo Fink (1998), como sujeito pensante consciente, assim como afirmava a filosofia cartesiana. O sujeito surge das imagens ideais com as quais a criança no estágio do espelho aprende a se identificar, ou seja, das imagens constituídas daquelas da própria criança no espelho. Fink (1998) diz que essas imagens, nesse momento, podem ser entendidas como ideais, pois "apresenta[m] uma aparência superficial unificada semelhante àquela imagem dos pais muito mais capazes, coordenados e poderosos" (Fink, 1998, p. 57). São as imagens investidas que a criança internaliza, assim como outras imagens ideais derivadas dela e refletidas pelo outro parental. Como exemplo temos, segundo Fink (1998), os ditos "boa menina" ou "menina má".

Os atos na adolescência são compreendidos a partir da leitura do Seminário, livro 10, a angústia de Lacan (2005) como acting out ou passagem ao ato. Na passagem ao ato o sujeito frente a angustia pula fora da cena, não endereça nada ao outro. Já no acting out há um apelo do sujeito ao outro, 'alguma coisa que se mostra na conduta do sujeito, em que sua ênfase demonstrativa, sua orientação para o Outro, deve ser destacada' (Lacan, 2005, p. 137).

Calazans e Bastos (2010) nos esclarece que o acting-out, expressão que para os autores têm origem no agieren freudiano, indica a existência de algo que, por estar fora da cadeia associativa, mostrase a partir de um ato, de um agir. Já a passagem ao ato, denominada de conduta imotivada pela psiquiatria, escancara que o bem estar não deve obediência ao princípio do prazer.

$\mathrm{O}$ entendimento sobre o acting out e a passagem ao ato, nos faz compreender que os atos ditos infracionais podem referenciar "um fazer no lugar de um dizer" (Lacadée, 2011, p. 102). O trabalho com a escuta dos adolescentes que cumprem medida socioeducativa demonstra que seus atos podem ser compreendidos como uma maneira de tentar darem uma resposta a esse estado de vida puro e bruto ao qual foram entregues. Lacadeé (2011) chama atenção para o fato desses atos evidenciarem uma relação do sujeito com uma prática de gozo que tem ligação direta com os objetos de consumo. 
Recalcatti (2004) afirma que o sujeito valoriza o consumo de objetos oferecido como solução para a sua falta a ser e que essa busca associada à promoção do saber especialista, presente nos dias atuais como resposta à verdade, tem como consequência a anulação do sujeito do inconsciente. O autor defende que há uma questão preliminar a ser considerada para o trabalho dos analistas no âmbito social: fazer existir o sujeito do inconsciente.

Ao evocar a teorização lacaniana da questão preliminar, Recalcatti (2004) reconhece e toma como princípio a necessidade teórica e clínica de um tratamento preliminar no âmbito das psicoses para dizer da questão preliminar que refere-se o resgate do sujeito do inconsciente na clínica na atualidade.

É muito importante lembrar esta origem da questão preliminar em Lacan porque a clínica contemporânea confronta-se precisamente com a fraqueza estrutural e generalizada da metáfora paterna, com os efeitos - vários - do retorno do gozo no real que tornam irredutíveis os novos sintomas ao regime significante da equivalência sintoma = metáfora. (Recalcati, 2004, p.2)

Então, no contexto do cumprimento de uma medida socioeducativa, é preciso reconhecer o sujeito do inconsciente para que possamos discutir a questão da responsabilidade. Só a partir daí que o adolescente se percebe como autor de sua história, de seu ato, e passa a ter um lugar. Responsabilidade implica, então, em dar uma resposta a um outro a respeito daquilo que, via ato, gerou consequências. Nos casos destes adolescentes, consequências que implicaram na transgressão da norma jurídica que organiza a sociedade. Responsabilidade é responder por, mas para que isso ocorra, é preciso que alguém tenha perguntado.

O direito não pergunta ao sujeito sobre o seu ato; apenas aplica-se àquele que transgride a lei uma punição, como forma de fazer com que ele responda à sociedade pelas consequências da transgressão cometida. É uma resposta em que não há um reconhecimento do sujeito. Podemos dizer de uma desimplicação do sujeito em relação à infração que incide sobre a não responsabilidade, pois a resposta, para a psicanálise, só é possível se houver questionamento, se houver reconhecimento. Assim, a função do psicólogo na execução dessas medidas é fazer com que o adolescente possa se perguntar a respeito de seu ato, para então começar um processo de responsabilização subjetiva que só se dá a posteriori da aplicação da lei.

Recalcati (2004) nos indica que retomar a questão preliminar é possível quando se tem condições que possibilitam uma interpretação, ou seja, é preciso retificar primeiramente o Outro, 
aquele que ocupa o lugar de analista. "Trata-se de dizer sim ao sujeito, portanto de encarar um Outro que saiba não excluir, não anular, não refutar, não silenciar, não preencher, não sufocar" (Recalcati, 2004, p. 6) para que a escuta possa operar a partir da transferência do sujeito com esse Outro.

É a partir da questão preliminar sustentada por Recalcati (2004) que dizemos que responder por um ato não pode, para a psicanálise, ser sinônimo de cumprir uma medida socioeducativa, ou seja, cumprir uma norma. Para o Direito é satisfatório uma resposta pautada na pedagogia subjacente às diretrizes legais. Sabe-se, porém, que essa resposta jurídica de ordem socioeducativa não garante por si só uma mudança subjetiva. A lei é um Outro que impõe limites, mas é preciso que alguém, nesse processo de execução, implique o adolescente em seu ato. Nesse sentido, Besset, Cohen, Coutinho e Rubim (2007) nos ensinam que é preciso considerar os espaços de fala e de escuta favoráveis à emergência de sujeitos que possam fazer um uso pensante de sua cidadania. O que orienta a prática da psicanálise nessas instituições é a escuta que o psicólogo faz de cada sujeito, convocando-o a ser protagonista de sua história. Como nos afirma Besset (2004), falar a um outro, principalmente quando esse outro não se autoriza a saber previamente sobre aquele que fala, é um convite para refletir, e uma possibilidade de uma mudança subjetiva.

Seguindo esta trilha da aposta na escuta dos adolescentes que cumprem medidas socioeducativas, podemos citar o trabalho de Barra (2007) que demostra como o dispositivo psicanalítico oferece condições para que o sujeito possa responder por aquilo que the escapa. Rosário (2010), nessa mesma perspectiva, defende a tese de que pela palavra há a possibilidade de ressignificação do ato infracional.

A psicanálise sustenta sua diferença em relação às outras práticas e discursos ao privilegiar o que há de único em cada sujeito, trabalhando as intervenções necessárias, sempre na perspectiva do "caso a caso". Diante do exposto, considerar o sujeito que comete um ato infracional, e que diante desse ato inscreve seu sofrimento de maneira singular, implica refletir sobre a função da psicanálise nas instituições jurídicas.

Besset, Cohen, Coutinho e Rubim (2007) convidam-nos a pensar como o psicanalista pode, diante do desafio de trabalhar com o que "não cessa de não se escrever" (pág.29) fazer valer o discurso da psicanálise ao sustentar os espaços de escuta da singularidade. Nesses espaços, por exemplo, os dos programas de execução das medidas socioeducativas, o encontro com o psicólogo pode viabilizar uma saída que se dá em favor da emergência de sujeitos que podem, a partir de suas falas, posicionarem-se de forma responsável ante suas escolhas. Assim, faz-se necessário compreender o panorama de 
criação das medidas socioeducativas para pensar a articulação possível com a escuta psicanalítica.

\section{O ECA e o sujeito de direitos}

É recente a legislação que rege os direitos e deveres das crianças e adolescentes brasileiros. Criado em 13 de julho de 1990, o Estatuto da Criança e do Adolescente (ECA) instituiu-se como Lei Federal no 8.069, preconizando a Doutrina da Proteção Integral, cujo marco é o reconhecimento das crianças e adolescentes brasileiros como sujeitos de direitos. Podemos dizer que anteriormente a essa legislação as crianças e os adolescentes foram negligenciados por não terem sobre si um olhar diferenciado na sociedade.

Segundo Marcílio (1998), o primeiro episódio registrado no Brasil de ação do Estado voltada para o cuidado de crianças e adolescentes acontece no final do século XVII, quando uma autoridade pública, indignada ao encontrar crianças devoradas por cachorros e outros animais nas ruas, escreveu uma carta ao Rei em Portugal. Este, posteriormente, por intermédio do Governador-mor da Bahia, Dom J oão de Lencastre, mandou os oficiais providenciarem atendimento às crianças que eram deixadas nas portas das residências e instituições. Seu objetivo era claro:

A fim de evitar o horror e a desumanidade que então praticavam com alguns recém-nascidos, as ingratas e desamorosas mães, desassistindo-as de si, e considerando-as a vários lugares imundos com a sombra da noite, e de quando amanhecia o dia se achavam mortas e algumas devoradas pelos cães e outros animais, com lastimoso sentimento da piedade católica, por se perderem aquelas almas pela falta do sacramento do batismo. (Marcílio, 1998, p. 147)

No Brasil, especificamente na Bahia, em 1738, concretizou-se, com a primeira "roda dos enjeitados", o início de uma política de assistência à criança. Segundo Marcílio (1998), a "roda dos enjeitados", conhecida também como "roda dos expostos", era uma espécie de roleta giratória na parede da Santa Casa de Misericórdia, onde as crianças eram deixadas sem que fosse possível identificar quem as abandonara. Essa prática objetivava não só proteger as crianças como também salvaguardar a honra das famílias, pois a grande maioria das crianças abandonadas era de filhos ilegítimos da relação entre senhores e escravas. O objetivo dessa prática era salvar a vida dos recém-nascidos abandonados. Para evitar o envolvimento com a prostituição e a vadiagem, as crianças e adolescentes eram encaminhadas precocemente ao trabalho. 
Nesse sentido, é necessário mencionar que a roda dos expostos permitiu uma primeira reflexão sobre questões relacionadas ao abandono e ao descaso com as crianças que puderam ser assunto de debate na sociedade civil. Essas questões referiam-se tanto ao infanticídio praticado pelas mães quanto ao abandono e exposição dos filhos que elas não desejavam criar.

No cenário brasileiro das políticas públicas do governo republicano, podemos perceber uma preocupação em relação à criança no que concerne à manutenção da ordem social. Faleiros (2004) nos diz que a política dessa época deu origem à criação de instituições, os reformatórios, nos quais a inscrição da criança na política social se dava não como sujeito, mas como objeto de controle. As primeiras leis em defesa das crianças surgiram no século XIX, por influência dessa demanda social protetiva, bem como pelo interesse de compreender as causas dos delitos e infrações a elas imputadas.

No Brasil, em 1927, foi decretado o Código de Menores, primeiro projeto de lei que dispõe sobre alguns direitos da criança e do adolescente. Esse código tratava da infância e adolescência pelo viés assistencialista e protetivo, estabelecendo que todos os menores de 18 anos de idade, desde que abandonados ou delinquentes, estariam submetidos à tutela da autoridade competente e sujeitos às medidas de assistência e proteção, como a proibição do trabalho infantil e a impunidade até os 14 anos de idade. Previa, também, a destituição do pátrio poder e da tutela em casos de atitudes anti-sociais cometidas contra as crianças, reconhecendo assim de forma sutil que elas poderiam sofrer violências por parte de seus responsáveis. Segundo Marcílio (1998), o discurso da assistência social e do Código de Menores de 1927 definiu um novo projeto jurídico e institucional no Brasil: não punitivo, mas recuperador e paternal, assim, voltado para os menores. O termo "menor" era usado para designar as crianças e adolescentes que se encontravam em situação irregular, e tornou-se "o discriminativo da infância desfavorecida, delinquente, carente e abandonada" (p. 195). Para reafirmar seu caráter protetivo, a legislação brasileira propôs ainda a criação em 1964 da Fundação Nacional de Bem-Estar do Menor (FUNABEM), que era um órgão de proteção cujo objetivo era prevenir e corrigir a causa dos desajustamentos, visando à reintegração do menor "desajustado" na família e na sociedade.

Em 1979, o Código de Menores foi reformulado com o objetivo de contemplar em seus artigos o proposto pela Declaração Universal dos Direitos da Criança, de 1959, dando origem ao Estatuto do Menor. Assim, a política de atendimento à criança e ao adolescente passou a considerar a proteção como direito destes, e dever do Estado. Podemos perceber o aparecimento, de modo implícito, do princípio do melhor interesse no texto da lei. Porém, mesmo assim, não foi possível acabar com os princípios anteriores, pois, nesse código, é 
legalmente reconhecida a Doutrina da Situação Irregular, o que criou a ideia do menor "em situação irregular". O Estatuto do Menor surgiu como um conjunto de leis relativo à definição da situação irregular, propondo o tratamento e a proteção dos menores que se encontravam nessa situação. Esse estatuto não contemplava a criança como um sujeito de Direito, tornando-a apenas objeto de intervenção da família, do Estado e da sociedade.

Depois de vários questionamentos dos órgãos nacionais e internacionais de proteção à criança e ao adolescente, temos, recentemente, na legislação brasileira, um conjunto de leis que legitimam a criança como um sujeito de Direito. Assim, em 1990, com o Estatuto da Criança e do Adolescente, Lei no 8.069, a legislação brasileira que trata especificamente dos direitos e deveres das crianças em nosso país passou a vigorar com a doutrina da proteção integral. Elevou-se o status das crianças e adolescentes, que deixaram de ser denominados "menores", e passaram a ser reconhecidos como sujeitos de Direito em condição peculiar de desenvolvimento. A sociedade reconheceu, por meio do ECA, que as crianças e adolescentes, por serem pessoas em condição especial de desenvolvimento, merecem a proteção integral e especial da família, da sociedade e do Estado.

De acordo com a doutrina do ECA, a concretização dos direitos dos quais são titulares crianças e adolescentes é assegurada a todos, sem distinção, e não somente aos menores abandonados ou delinquentes. Em seu artigo 1으, encontramos assim declarado: "esta lei dispõe sobre a proteção integral à criança e ao adolescente". A proteção integral baseia-se no princípio do melhor interesse da criança, que foi sutilmente evocado na Declaração Universal dos Direitos da Criança, em 1959. A partir do momento em que é legitimada, com o ECA, a doutrina da proteção integral, as crianças e os adolescentes são reconhecidos como sujeitos de Direito, tendo seus interesses respeitados acima de qualquer outro, seja da família, da sociedade ou do Estado.

Assim, com o Estatuto da Criança e do Adolescente, o termo "sujeito" advém como conceito inovador, que faz dessa legislação uma valiosa conquista no campo do Direito. Este termo, porém, possui concepções diferentes quando associado ao discurso do direito e ao da psicanálise. O Direito é uma ciência de fundamento positivista que trabalha no campo da razão, no qual a lei é a expressão máxima da normatividade socialmente produzida e legalizada em códigos universais. Diante das violações e da violência, o Direito é chamado para instituir e resgatar, por meio de suas leis, a ordem. Seu objetivo é a produção de um saber racional que regulamenta, de forma universal, os procedimentos de solução dos conflitos segundo as prescrições legais. Já a psicanálise rompe com a lógica universal, e 
demonstra que a verdade do sujeito é singular, e que ela está presente em seu discurso, e não na objetividade discursiva.

Retomemos Freud (1974), que já afirmava, em seu texto "Mal-estar na civilização", de 1929, que não existe verdade totalizadora; nem mesmo o Direito, enquanto ciência da razão, alcança esse mérito. Considerando que o mal-estar é próprio da cultura, podemos dizer que as leis culturais ordenam o caos, contornando-o. Mas temos, paralela a essas leis, outra legalidade, que é a de cada sujeito em particular. Assim, como nos afirma Quinet (2003), podemos apontar a existência de duas leis. A primeira é a lei simbólica, que está do lado da psicanálise e rege os homens na condição de seres que habitam a linguagem. A segunda é a lei dos códigos que regulam as relações dos homens em sociedade, e que tem por base o princípio da razão.

Constatamos diariamente no trabalho com a execução das medidas socioeducativas que não basta um trabalho orientado apenas pela premissa do ECA de que o adolescente é um sujeito do Direito, porque nesse caso ele é considerado sem história de vida, e os encaminhamentos são orientados em nome da doutrina de proteção integral, seguindo-se um protocolo. Com isso, as intervenções, que deveriam ser construídas no "caso a caso", são direcionadas em prol do saber universal de quem cumpre a lei, e podem não produzir um efeito de responsabilização.

O ECA, em seus 267 artigos, garante os direitos e deveres de cidadania a crianças e adolescentes, e atribui a responsabilidade dessa garantia aos setores que compõem a sociedade, sejam estes a família, o Estado ou a comunidade. Ao longo de seus capítulos e artigos, o Estatuto discorre sobre as políticas referentes à saúde, à educação, à adoção, à tutela e a questões relacionadas aos adolescentes autores de atos infracionais.

O trabalho com o adolescente autor de ato infracional considera, portanto, o texto legal do ECA, que propõe como intervenção seis medidas socioeducativas. É preciso enfatizar que a concepção de sujeito de Direito presente no texto dessa lei nos faz romper com a lógica menorista, ao propor um trabalho cujo objetivo está para além da pura punição, e compreende a tentativa de reinserção social, de fortalecimento dos vínculos familiares e comunitários nesses casos. Assim, as medidas descritas no ECA, em seu artigo 112, são aplicadas aos adolescentes com idade definida entre 12 e 18 anos aos quais se atribui a prática de atos infracionais. Essas são, segundo o ECA, as medidas socioeducativas: I. Advertência; II. Obrigação de reparar o dano; III. Prestação de serviço à Comunidade; IV. Liberdade Assistida; V. Inserção em regime de semiliberdade; VI. Internação em estabelecimento educacional (Lei n. 8.069, 1990).

Apesar de romper com a lógica menorista, podemos dizer que a concepção de sujeito implícita no ECA assemelha-se à do sujeito 
cartesiano enquanto um sujeito que pensa e que, pela via da razão, consegue responder pelo ato infracional cometido, modelando seu comportamento. Para garantir o cumprimento da lei criam-se então diversas diretrizes e normas que descrevem o que se espera do adolescente no cumprimento de sua medida socioeducativa. Como é preciso uma diretriz universal, foi necessário, ao contexto das políticas públicas responsável pela execução das medidas socioeducativas, a criação de um projeto de lei que legislasse sobre a maneira de executá-las. Então, o Sistema Nacional Socioeducativo (SINASE), lei 12594, entra em vigor em 18 de janeiro de 2012. O SINASE é composto por princípios, regras e ações jurídicas, políticas, financeiras e administrativas, presentes no contexto do trabalho com o adolescente autor de ato infracional, e propõe ações desde a apuração do ato até a execução das seis medidas socioeducativas.

O SINASE fornece as diretrizes e os eixos estratégicos para a execução das medidas socioeducativas de meio aberto e fechado e, nesse sentido, é um articulador dos sistemas do Direito - sistema educacional, sistema de justiça e segurança pública, sistema único de saúde e sistema único de assistência social - presentes no ECA, sob o caráter da Doutrina da Proteção Integral. Ao propor metodologias à gestão socioeducativa, o SINASE visa integrar esses diversos sistemas em prol de uma intervenção de caráter duplo: sancionatória, já que é imposta ao adolescente como resposta do Estado à infração cometida, mas principalmente socioeducativa, pois ao ser reconhecido em sua condição peculiar de desenvolvimento o adolescente deverá ter todos os seus direitos garantidos. Na mesma direção do ECA, podemos dizer que o SINASE trabalha com a lógica da responsabilização atrelada ao cumprimento do estabelecido em suas normativas.

Como exemplo, temos a construção da rede socioassistencial, meio indispensável no alcance da inclusão dos adolescentes no convívio social. Entretanto, é preciso fazer dessa prática de trabalho em rede não um instrumento de inclusão em nome de um Direito, mas um instrumento que torna possíveis novos arranjos e articulações que poderão viabilizar, na vida de cada adolescente, um processo de inclusão social particular, que o auxiliará no processo individual de responsabilização. Ou seja, é preciso construir outras saídas para a sua vida, que não a infração. Se reduzirmos a escuta desses adolescentes à apreensão dos sinais que indicam comportamentos que foram modificados com o intuito de responder à norma e obter o cumprimento de sua medida socioeducativa, estaríamos trabalhando em uma lógica em que a escuta passa a cumprir não mais que uma função utilitária. Ela serviria apenas para a comunicação em seu caráter informativo, deixando de lado o sentido que pode estar por detrás dela. 


\section{Escuta como um operador de subjetivação}

A psicanálise trabalha em uma posição diferente do discurso jurista, das perícias e dos testes psicológicos. Ela sustenta a particularidade de cada caso e a singularidade de cada sujeito, rompendo com as intervenções de caráter universal. Para além da elaboração de laudos e pareceres, o psicólogo orientado pela psicanálise visa possibilitar o trabalho de resgate da dimensão subjetiva dessas crianças, possibilitando a elas serem sujeitos envolvidos no processo jurídico que Ihes diz respeito, e não objetos inertes diante da aplicabilidade da lei.

Altoé (2004) nos faz refletir sobre o mal-estar que se coloca nas instituições quando a proposta é romper com o saber que universaliza. A autora diz que o fazer a partir do "caso a caso" dá trabalho, pois pede sempre a construção de uma nova intervenção e, com isso, o psicólogo tem de ser criativo.

A abordagem psicanalítica permite que a criança ou jovem seja percebido na sua subjetividade, na sua história, e não reduzido aos seus problemas, déficits ou carências, como indica a denominação "criança carente". E também abre a possibilidade de intervir no nível da compreensão dos conflitos permitindo evitar que se tomem medidas precipitadas ou intempestivas com as crianças com consequências difíceis na relação com o adulto e, também na dinâmica institucional (p. 54).

O jurídico reforça a lei igual para todos, mas para uma aplicabilidade embasada não apenas na razão e na neutralidade dos fatos, é preciso abrir espaço para o particular aparecer. Nesse momento, devemos escutar o adolescente como um sujeito de desejo, de uma história de vida única. Embora seja preciso normas universais como o ECA e o SINASE para direcionar não só a criação de políticas públicas, mas também os profissionais que atuam nessa área, é possível subverter a universalidade e escutar o particular na política pública. Não podemos abrir mão do pressuposto do sujeito do Inconsciente como referência básica da intervenção.

No Brasil, as pesquisas sobre a prática profissional dos psicanalistas nas políticas públicas ainda são recentes (Alberti, 2000; Figueiredo, 1997). Ainda assim, acreditamos que a psicanálise tem muito a contribuir para as intervenções nesse campo. Como revelam Lara e Ribeiro (2009), a psicanálise não dissocia a teoria da prática, e alerta o profissional de que escutar a demanda não é respondê-la.

[Escutar] é diferente de satisfazê-la prontamente. Essa posição permite a ruptura com a ótica assistencialista que prioriza o aspecto material [das necessidades] em detrimento das urgências subjetivas e sociais das comunidades - o que, em 
última instância, é uma forma ideológica de manutenção das desigualdades sociais. ([s.p.])

A teoria psicanalítica oferece, para o profissional, elementos para trabalhar sua posição diante do outro, e a prática da psicanálise permite-nos escutar o sujeito do inconsciente. Dessa forma, podemos apreender as falácias narcísicas, diferenciar demanda de desejo, convidar a aparição do sujeito que se encontra eclipsado pelo sintoma e preso nas redes da compulsão à repetição. É preciso pensar na intervenção como uma forma de retificação subjetiva. Como revela Couto (2004), a retificação é um dos elementos centrais do trabalho de um analista: "A retificação pode ser considerada, portanto, como 'subjetiva', pois conduz o paciente a mudar a sua posição de sujeito frente aos modos permanentes pelos quais ele constitui os seus objetos". (p. 277) Somente a partir da escuta do que é particular a cada caso é possível ao técnico trabalhar a possibilidade de uma retificação como a sugerida por Couto (2004). Oferecer um lugar para o sujeito falar e suportar ser o destinatário desse dizer é condição para que o adolescente possa se perguntar sobre suas atuações.

A responsabilização jurídica inaugura, então, a possibilidade do trabalho de responsabilização subjetiva, que em poucas palavras pode ser entendida como a construção de outras respostas, que não a infração, frente aos impasses da vida. (Souza \& Moreira, 2010) Buscamos a exemplificação através de um fragmento reconstruído de caso.

\section{Convocar o sujeito: fragmentos de um caso}

Tomemos o caso de Bia, uma adolescente de 15 anos que chega para cumprir medida socioeducativa após ser apreendida por ato análogo ao crime de tráfico de drogas. No início do cumprimento de sua medida Bia localiza que se envolveu com a venda de droga há pouco tempo, e que sua entrada na criminalidade se deu quando resolveu sair de casa, pois já não aguentava mais conviver com as agressões do padrasto e com a falta de atenção da mãe para com os filhos. Ela diz que a mãe cuidava deles, mas não dava "aquela atenção de mãe" de que ela precisava. A mãe de Bia apresenta um discurso do cuidado e não do afeto, o que leva a adolescente a dizer do abandono de sua mãe.

Podemos dizer que Bia, via atuação, denuncia certo abandono. Apesar das preocupações da mãe como por exemplo com a freqüência na escola e alimentação, esta não hesitava em deixar os filhos sozinhos para sair e se divertir. Também colocava as crianças para vender os salgados que fazia tendo como desculpa a necessidade de ter dinheiro para suprir suas necessidades. 
Ao cometer ato infracional ela vai de encontro com a lei de regulação social, que the impõe uma medida socioeducativa. Essa medida impõe-lhe uma sanção e, ao mesmo tempo, impõe-lhe a garantia de seus direitos, com os quais se espera pôr fim a seu abandono.

O termo "abandono" aparece com frequência nas falas de Bia, porém associado ao abandono material. Diante disso, ela inicia uma demanda desenfreada à técnica, pedido-Ihe vales-transporte, cesta básica, encaminhamentos diversos para cursos, trabalho protegido. Cabe dizer que, como a família era beneficiária de outros programas, algumas dessas demandas já haviam sido ofertadas, e a adolescente não conseguia se engajar em nenhuma delas. Como não é atendida em sua urgência, Bia, irritada, questiona a técnica sobre aquele espaço. Segundo ela, o Juiz havia dito que ali ela seria encaminhada para cursos e trabalho. Como resposta, a técnica diz que ali era também um espaço de escuta; que primeiro Bia precisava entender o que queria, para que seus encaminhamentos fossem realizados.

Precisamos localizar a partir da escuta dos adolescentes envolvidos com a criminalidade a sua posição de sujeito, ou seja, qual a satisfação que têm com seus atos e qual implicação que têm com as justificativas que criam e com as queixas que apresentam.

Bia, então, permite a si mesma dizer das mágoas da sua infância, de seus abandonos, das suas infrações. Foi possível perceber, durante o relato, que sua história de vida é marcada por violência e abandono. Bia diz ter mágoas da mãe, relativas à sua infância. A adolescente relata que a mãe sempre foi ausente em sua vida, e que ela, Bia, aprendeu cedo a se virar. Ela consegue localizar esse fato como um dos fatores que acabaram por influenciar seu modo de viver, e a lançaram nessa vida bruta, "vida dura do tráfico". Podemos dizer que mesmo sua família sendo assistida pela Assistência Social, Bia, em suas errâncias, buscou ser amparada e, assim, como nos diz Calligaris (1996), ao ser privada do objeto do qual precisava para ser alguém, arrisca-se a não ser ninguém.

Depois de um determinado tempo Bia consegue localizar que primeiro precisa se entender, e então faz sua primeira "demanda lapidada" à técnica: ela solicita ser encaminhada para um atendimento psicológico no Posto de Saúde. A adolescente diz já ter ido ao psicólogo outra vez, levada por sua mãe, mas que, naquela época, não achou que era importante, e abandonou. Relata que antes não queria saber de sua vida, mas que agora entende que precisa resolver "algumas pendências do passado", por isso seu pedido. Podemos então entender que só a partir da escuta de Bia, mesmo em serviço que se difere da clínica, foi possível compreender sua posição de sujeito, e intervir articulando o que é da ordem da norma, da execução de uma medida, ao que Ihe é subjetivo. Assim, a oferta de um espaço de escuta para Bia permitiu o surgimento de um novo 
sujeito, com desejos e projetos, que ultrapassa o lugar das queixas e demandas assistencialistas.

\section{Considerações finais}

É possível compreender que a ideia de abandono que justificou a criação de leis e políticas públicas a favor das crianças e adolescentes brasileiras é da ordem da falta material e da satisfação das necessidades vitais. Dizer que essas crianças e adolescentes são lançados à sorte da vida implica dizer, segundo a psicanálise, que eles não receberam amparo. O amparo que implica o outro como referência, o outro que oferece algo além do material, que o reconhece enquanto sujeito. Portanto, podemos dizer que, mesmo com a criação dessas leis que tornam o amparo um dever do Estado, esses jovens permaneceram abandonados.

Podemos concluir dizendo que a psicanálise traz a escuta como contribuição a estes espaços do jurídico, da regulação social, na medida em que, através dela, é possível sinalizar sobre a responsabilização subjetiva desses adolescentes. É a partir da infração que o sujeito pode, no encontro com o profissional que irá acompanhá-lo, enfrentar seu abandono em um ato, não de infração, mas de subjetivação, que implica a construção de novas saídas.

Refletir sobre o estatuto do sujeito no cumprimento das medidas socioeducativas como intervenção do Estado nos casos de adolescentes que cometeram ato infracional impõe-nos a tarefa de pensar a concepção de sujeito pelo viés jurídico e pelo da psicanálise. Como refletir sobre o tema da responsabilidade no cumprimento dessas medidas tendo essas duas categorias de sujeito entrelaçadas? As medidas socioeducativas propõem a reinserção social, a readaptação, o ajustamento social, a integração à família e à sociedade como eixos fundamentais na garantia de direitos. Mas, não podemos perder de vista que “(...) sujeito e responsabilidade se equivalem, para a psicanálise - um termo não pode ser concebido sem o outro. Considera-se, assim, a responsabilidade no sentido de uma resposta, que é sempre de um sujeito." (Salum, 2012, p. 169).

Muito embora essas medidas tenham um caráter socioeducativo e ao mesmo tempo sancionatório, sua operacionalização pode se dar a partir de ações embasadas na concepção de que o adolescente é um sujeito único e singular. È por meio da escuta de sua história de vida que as intervenções de âmbito universal, podem ter um alcance frente à particularidade de cada caso.

Salum (2012) nos diz que podemos fazer do espaço do acompanhamento da medida um novo espaço onde a oferta da escuta convoca esses adolescentes a falar, a construir novos laços e retomar sua vida retificando sua trajetória de violência. 


\section{Referências}

Alberti, S. (2000). Psicanálise: a última flor da medicina. In S. Alberti \& L. Elia (Orgs.), Clínica e pesquisa em psicanálise (pp. 37-55). Rio de Janeiro: Rios Ambiciosos.

Altoé, S. (2004). A Psicanálise pode ser de algum interesse no trabalho institucional com crianças e adolescentes? In S. Altoé, Sujeito do direito, sujeito do desejo: direito e psicanálise (pp. 51-60). Rio de Janeiro: Revinter, 2004.

Barra, M. B. (2007). A clínica psicanalítica em um ambulatório para adolescentes em conflito com a lei. Estudos e Pesquisa em Psicologia, 7(3), 2007. Recuperado em 13 junho, 2013, de $<$ http://pepsic.bvsalud.org/scielo.php?script=sci_arttext\&pid=S1808$42812007000300006 \&$ lng $=p t \& n r m=$ iso $>$

Besset, V. L. (2004). O tratamento psicanalítico no tempo dos psicofármacos. Pulsional, 17(177), 43-50.

Besset, V. L., Cohen, R. H. P., Coutinho, L. G, \& Rubim, L. M. (2007). A Psicanálise na cultura: novas formas de intervenção. Psicologia em Revista, 13(1), 27-40. Recuperado em 15 maio, 2011, de <http://www. pucminas.br/institutos/psicologia_revista.php>

Bezerra, B. (1989). Subjetividade Moderna e o Campo da Psicanálise. In J. Birman (Org.), Freud, 50 Anos depois (pp. 218-239). Rio de Janeiro: Relume Dumará.

Calazans, R. \& Bastos, A. (2010). Passagem ao ato e acting out: duas respostas subjetivas. Fractal: Revista de Psicologia, 22(2), 245-256.

Calligaris, C. (1996). Um narcísico mundo novo. Boletim de Novidades da Livraria Pulsional, 86(9), 72-80.

Descartes, R. (1983). Meditações metafísicas (pensadores). São Paulo: Abril Cultural. (Obra original publicada em 1641).

Faleiros, E. T. S. (2004). O fio da meada: a denúncia e a notificação de situações de abuso sexual contra crianças e adolescentes. In Comitê Nacional de Enfrentamento à Violência Sexual Contra Criança e Adolescente (Org.), Colóquio sobre o sistema de notificação em violência sexual contra criança e adolescente (Relatório final). Brasília: Abaré/ Autor.

Figueiredo, A. C. (1997). Vastas confusões e atendimentos imperfeitos: a clínica psicanalítica no ambulatório público. Rio de J aneiro: Relume Dumará.

Fink, B. (1998). O sujeito lacaniano entre a linguagem e o gozo. Rio de J aneiro: Jorge Zahar.

Freud, S. (1974). O Mal-estar na Cultura. In Edição standard brasileira das obras psicológicas completas de Sigmund Freud (J. Salomão, trad., Vol. 21, pp. 81-171). Rio de Janeiro: Imago. (Trabalho original publicado em 1930[1929]). 
Lacadée, P. (2011). O despertar e o exílio: ensinamentos psicanalíticos da mais delicada das transições. Rio de Janeiro: Contra Capa.

Lacan, J. (1998). O estágio do espelho como formador da função do eu. In Escritos. Rio de Janeiro: Jorge Zahar. (Trabalho original publicado em 1949).

Lacan, J. (2005). Passagem ao ato e acting out In: O seminário, livro 10: a angústia. Rio de Janeiro: Jorge Zahar. (Trabalho original publicado em 1963).

Lara, N., J r., \& Ribeiro, C. T. (2009). Intervenções psicossociais em comunidades: contribuições da psicanálise. Psicologia e Sociedade, 21(1), 91-99. Recuperado em 4 janeiro, 2010, de <http://www.scielo.br/pdf/psoc/v21n1/11.pdf>

Lei n. 8.069, de 13 de julho de 1990. Dispõe sobre o Estatuto da Criança e do Adolescente, e dá outras providências. Brasília, DF: Câmara dos Deputados.

Lei n. 12594, de 18 de janeiro de 2012. Institui o Sistema Nacional Socioeducativo - SINASE. Brasília, DF: Câmara dos Deputados.

Marcílio, M. L. (1998). História social da criança abandonada. São Paulo: Hucitec.

Marin, I. da S. K. (1999). Sujeito, desamparo e violência. Revista Latinoamericana de Psicopatologia Fundamental, 2(3), 75-88.

Moreira, J. de O. (2003). Figuras da Alteridade no Pensamento Freudiano. Tese de Doutorado, Pontifícia Universidade Católica de São Paulo, São Paulo.

Moreira, J. de O. (2010). Retecendo as posições maternas junto à criança vítima de negligência ou abuso sexual: da mãe ideal à maternidade possível. In A. M. C. Guerra, \&J. de O.

Moreira (Orgs.), A psicanálise nas instituições públicas: saúde mental, assistência e defesa social (pp. 47-58). Curitiba: CVR.

Quinet, A. (2003). O gozo, a lei e as versões do pai. In G. C. Groeninga \& R. C. Pereira (Coord), Direito de Família e Psicanálise: rumo a uma nova epistemologia (pp. 55-66). Rio de Janeiro: I mago, 2003.

Recalcati, M. (2004) A questão preliminar na época do Outro que não existe. Latusa Digital, 1 (7), 1-12. Recuperado em 14 jun, 2013, de <http://www.latusa.com.br/pdf_latusa_digital_7_a2.pdf>

Rosario, Â. B. do. (2010). Grup̄o com adolescentes em privação de liberdade: circulação da palavra como possibilidade de ressignificação do ato infracional. Revista da SPAGESP - Sociedade de psicoterapias analíticas grupais do estado de São Paulo, 11(1), 66-76. Recuperado em 13 junho, 2013, de <http://pepsic.bvsalud.org/scielo.php?script=sci_arttext\&pid=S1677$29702010000100008 \&$ lng $=p t \& n r m=i s o>$

Salum, M. J. G. (2012). O adolescente, o ECA e a responsabilidade. In Revista Brasileira Adolescência e Conflitualidade, (6), 162-176. 
Recuperado em 14 jun. , 2013, de <http://periodicos.uniban.br/index. php?journal=RBAC\&page $=$ article\& op=view\&path\% 5B\% 5D=297\&path\% 5B\% 5D=236>

Souza, J. M. \& Moreira, J. O. (2010). Considerações acerca do estatuto do sujeito no cumprimento da medida socioeducativa. Trabalho apresentado no I Congresso Latino Americano de Psicanálise na Universidade. Resumo recuperado em 7 fev., 2011, de <http://www.pgpsa.uerj.br/trabalhos\%20completos>

\section{Endereço de para correspondência}

Juliana Marcondes Pedrosa de Souza

Programa de Pós-Graduação Stricto Sensu de Psicologia da PUC Minas. Av. Itaú, 525, Dom Cabral, CEP 30535-012, Belo Horizonte - MG, Brasil

Endereço eletrônico: juliana.marcondes@yahoo.com.br

\section{Jacqueline de Oliveira Moreira}

Programa de Pós-Graduação Stricto Sensu de Psicologia da PUC Minas. Av. Itaú, 525, Dom Cabral, CEP 30535-012, Belo Horizonte - MG, Brasil

Endereço eletrônico: jackdrawin@yahoo.com.br

Recebido em: 07/02/2012

Reformulado em: 19/06/2013

Aceito para publicação em: 02/07/2013

Acompanhamento do processo editorial: Rita Maria Manso de Barros

\section{Notas}

* Doutoranda em psicologia pela Pontifícia Universidade Católica de Minas Gerais, Bolsista Capes, Mestre em Psicologia pela Universidade Federal do Rio de Janeiro.

** Doutora em Psicologia Clinica pela Pontifícia Universidade Católica de São Paulo, Mestre em Filosofia pela Universidade Federal de Minas Gerais, Professora do Programa de Pós-Graduação em Psicologia da Pontifícia Universidade Católica de Minas Gerais (Mestrado/Doutorado), Psicóloga Clínica, Bolsista Produtividade PQ 2 CNPq. 